\title{
Stochastic Method for the Determination of Organ-Specific Averaged SAR in Realistic Environments at $950 \mathrm{MHz}$
}

\author{
Arno Thielens*, Günter Vermeeren*, Wout Joseph*, and Luc Martens* \\ (email:arno.thielens@intec.UGent.be, tel : +32 933 14918, fax:+32 933 14899) \\ *Department of Information Technology, Ghent University / iMinds \\ Gaston Crommenlaan 8, B-9050 Ghent, Belgium
}

Running title: $\mathrm{SAR}_{\mathrm{osa}}$ in realistic environments at $950 \mathrm{MHz}$

Grant sponsor info: The research leading to these results has received funding from the European Union's Seventh Framework Programme [FP7/2007-2013] under grant agreement no 244149 and the FWO-V (Research Foundation-Flanders) under project no 3G004612.

Online supporting Material- Additional supporting material may be found in the online version of this article.

Abstract- The organ-specific averaged specific absorption rate $\left(\mathrm{SAR}_{\mathbf{0 s a}}\right)$ in a heterogeneous human body phantom, the Virtual Family Boy, is determined for the first time in (five) realistic electromagnetic environments at the Global System for Mobile communications downlink frequency of $950 \mathrm{MHz}$. We propose two methods, based upon a fixed set of finite- 
difference time-domain (FDTD) simulations, for generating cumulative distribution functions for the $\mathrm{SAR}_{\text {osa }}$ in a certain environment: an accurate vectorial cell-wise spline interpolation with an average error lower than $1.8 \%$ and a faster scalar linear interpolation with a maximal average error of $\mathbf{1 4 . 3 \%}$. These errors are dependent on the angular steps chosen for the FDTD simulations. However, it is demonstrated that both methods provide the same shape of the cumulative distribution function for the studied organs in the considered environments. The $\mathrm{SAR}_{\mathrm{osa}}$ depends on the considered organ and environment. Two factors influencing the $\mathrm{SAR}_{\mathrm{osa}}$ are investigated for the first time: the conductivity over density ratio of an organ and the distance of the organ's center of gravity to the body's surface and the exterior of the phantom. A non-linear regression with our model provides a correlation of 0.80 . The $\mathrm{SAR}_{\text {osa }}$ due to single plane-wave exposure is also investigated: a worst-case single plane-wave exposure is determined for all studied organs and has been compared with realistic $S A R_{0 s a}$ values. There is no fixed worst-case polarization for all organs and for the studied organs a single plane-wave exposure condition that exceeds $91 \%$ of the $\mathrm{SAR}_{\mathrm{osa}}$ values in a certain environment can always be found.

Key Words- organ-specific averaged SAR, realistic electromagnetic environment 


\section{INTRODUCTION}

Absorption of radio frequency (RF) electromagnetic radiation in the human body can be described using the specific absorption rate (SAR). The International Commission on NonIonizing Radiation Protection [ICNIRP, 1998] and the Institute of Electrical and Electronics Engineers [IEEE, 2005] have defined basic restrictions (or limits) on different averaged SAR values. These averaged values are: the whole-body averaged SAR $\left(\mathrm{SAR}_{\mathrm{wb}}\right)$ and the peak $10 \mathrm{~g}$ and $1 \mathrm{~g}$ averaged $\mathrm{SAR}\left(\mathrm{SAR}_{10 \mathrm{~g}}, \mathrm{SAR}_{1 \mathrm{~g}}\right)$, where the maximum value of the SAR averaged over $10 \mathrm{~g}$ and $1 \mathrm{~g}$ cubes is considered. From these basic restrictions, reference levels for incident electromagnetic fields (EMFs) are extracted [ICNIRP, 1998; IEEE, 2005]. The majority of the studies in this field aim to investigate whether the general population is protected by these reference levels and whether there is compliance with the basic restrictions in more realistic situations. However, these quantities are determined based on the thermal effect of RF radiation and do not provide detailed information about absorption in the body. Moreover, differences are expected to occur in the SAR in different organs [Bernardi et al., 2000; Christ et al., 2010a], due to anatomical and electromagnetic differences, which is to be investigated using an organ-specific quantity. The organ-specific averaged $\mathrm{SAR}\left(\mathrm{SAR}_{\mathrm{osa}}\right)$ is introduced in order to study the localization of absorption of the energy of EMFs in the body and as an important input for epidemiological and clinical research of RF radiation. The effects that are investigated in these studies can be localized [Valentini et al. 2007; Baste et al., 2008]. Effects of RF radiation on the central nervous system are investigated in particular [Huber et al., 2003; Regel et al., 2007; Cardis et al., 2010; Aydin et al., 2011;Larjavaara et al., 2011]. The SAR osa $_{\text {provides a mass }}$ averaged SAR value for every organ or tissue in the body and is related to the $\mathrm{SAR}_{\mathrm{wb}}$, since a mass average of all $\mathrm{SAR}_{\text {osa }}$ values equals the $\mathrm{SAR}_{\mathrm{wb}}$. 
The $\mathrm{SAR}_{\mathrm{osa}}$ in realistic human body phantoms has already been studied in the vicinity of a base station antenna [Bernardi et al., 2000], deterministically for near-field (NF) exposure conditions [Christ et al., 2010a], and more specifically for different brain regions [Huber et al., 2003; Regel et al., 2007; Crespo-Valero et al., 2011], but not yet in a stochastic manner, nor in realistic environments. This study aims at developing a finite-difference time-domain (FDTD) based method to determine the $\mathrm{SAR}_{\mathrm{osa}}$ under realistic far-field (FF) exposure and investigates the dependence of the $\mathrm{SAR}_{\mathrm{osa}}$ on the environment.

In the past, a deterministic approach has been used, to estimate the SAR in heterogeneous phantoms, both for NF and FF exposure conditions [Hirata et al., 2007, 2009; Findlay et al., 2008, 2009; Dimbylow et al., 2009, 2010; Kühn et al.,2009; Bakker et al., 2010, 2011b; Uusitupa et al., 2010; Conil et al., 2011]. More specifically, in order to estimate FF exposure, the SAR is calculated for different single plane-wave (SPW) exposure conditions coming from basic directions [Bakker et al., 2010; Conil et al., 2011] or worst-case plane wave exposure [Bakker et al., 2011b]. More recent studies on FF exposure aim at determining SAR for realistic environments. In a realistic environment however, SPW exposures almost never occur [Olivier, 2007]. The power absorbed in an organ in a realistic exposure condition can only be assessed using a stochastic approach. To estimate $\mathrm{SAR}_{\mathrm{osa}}$ of a certain organ, a statistically relevant number of exposure conditions have to be considered. To do this numerically would take thousands of time-consuming FDTD simulations and hundreds of Terabytes of storage space. A fast stochastic method is therefore used to avoid executing a large number of FDTD simulations. This method is based on statistical models for realistic exposure conditions [Olivier, 2007] and uses a set of EMFs induced by plane waves coming from some basic directions. These EMFs are combined to estimate the effect of a random plane wave or an exposure condition constituted by multiple 
plane waves, for which normally a new FDTD simulation should be executed. This approach is already demonstrated for $\mathrm{SAR}_{\mathrm{wb}}$ in spheroidal human body models [Vermeeren et al., 2008] and for heterogeneous human body models [Iskra et al., 2011; Vermeeren et al., 2013].

The objective of this paper is to develop a stochastic method for the organs of heterogeneous human body phantoms in realistic exposure conditions and thus determine the $\mathrm{SAR}_{\text {osa }}$ for the first time stochastically for complex realistic environments. Other novel aspects of this study are a comparison of this $\mathrm{SAR}_{\text {osa }}$ in realistic environments with the $\mathrm{SAR}_{\mathrm{osa}}$ induced by single plane waves and an investigation of two different contributors to the SAR $\mathrm{osa}_{\mathrm{a}}$ : the conductivity-density ratio and the distance of an organ's center of gravity to the environment.

\section{MATERIALS AND METHODS}

\section{Configurations}

The $\mathrm{SAR}_{\mathrm{osa}}$ has been investigated numerically for realistic FF exposure conditions. Five different exposure scenarios at $950 \mathrm{MHz}$ are investigated. The used method will be demonstrated using some selected organs.

\section{Anatomical human body model}

The Virtual Family Boy (VFB) [Christ et al., 2010b] is selected as human body model or phantom. This model is shown in Figure 5 (included in supplementary online materials) and has been created using magnetic resonance imaging (MRI) of a 6 year old male. The boy is $1.10 \mathrm{~m}$ tall and has a mass of $16.6 \mathrm{~kg}$. The Gabriel database [Gabriel and Gabriely, 1996] provides the dielectric properties of the phantom's different tissues. The model consists of 75 predefined tissues, from these 38 have been selected to demonstrate our tool: the different tissues of the 
central nervous system - since the brain can be influenced by RF radiation on a physiological level [Huber et al., 2003; Regel at al., 2007; Crespo-Valero et al., 2011], tissues of the peripheral nervous system, and other vital organs and glands in the body. Parts of the gastrointestinal system are not studied in this paper because the absorption in these organs depends on their contents. Simulations using various contents of the gastrointestinal system (air, muscle tissue and surrounding tissue) with frontally incident plane waves have been performed and show that a variation up to $86 \%$ in $\mathrm{SAR}_{\mathrm{osa}}$ can exist within the organs of the gastrointestinal system. Parts of the skeleton, the skin, fat and connective tissue are not dealt with in this study, since the $\mathrm{SAR}_{\text {osa }}$ will not be an appropriate quantity to study localized absorption in these larger organs or tissues.

\section{Finite-Difference Time-Domain Simulations}

The EMFs inside the phantom, which are necessary to calculate the $\mathrm{SAR}_{\mathrm{osa}}$, are estimated using the FDTD method. A simulation domain is defined around the VFB and is bounded by perfectly matched layers (PML). This simulation domain is then discretized using a rectilinear grid. As a rule of thumb the grid step should be smaller than $\lambda / 10$, with $\lambda$ the shortest wavelength in the simulation domain, for a stable simulation [Hand, 2008]. A small grid step is preferred, as it will lead to more spatial resolution and thus accuracy, but is accompanied with a small time step due to the Courant limit for stability. A shorter time step will give rise to longer simulations before reaching a steady state solution and more data processing. The Global System for Mobile communications (GSM) downlink frequency of $950 \mathrm{MHz}$ has been chosen to demonstrate our method. For $950 \mathrm{MHz}$ a grid step of $2 \mathrm{~mm}$ has been used [Vermeeren et al., 2012], which

corresponds to a time step of $3.810^{-12} \mathrm{~s}$. The grid step of $2 \mathrm{~mm}$ allows the skin of the model to be resolved appropriately [Christ et al., 2006]. This resulted in a total number of $19.2 \times 10^{6}$ cells. The simulations are terminated after 12 periods when a steady state is reached. The commercial 
tool SEMCAD-X (Schmid \& Partner Engineering AG (SPEAG), Switzerland) is selected for our FDTD simulations. The simulations are accelerated using Graphics Processing Unit (GPU) based computing provided by SPEAG.

\section{Methodology}

To determine the exposure of the VFB in realistic FF environments, a statistically relevant number of exposure conditions or exposure samples have to be considered in every environment [Vermeeren et al., 2008, 2012; Iskra et al., 2011]. A FF exposure condition consists of a number of plane-waves, distributed according to certain statistics. Every exposure condition is characterized by certain variables: the number of incident plane waves in the exposure condition $\left(\mathrm{N}_{S}\right)$, their amplitude $(\mathrm{A})$, polarization $(\psi)$, phase $(\alpha)$, azimuth angle $(\varphi)$, and elevation angle $(\theta)$. A distribution exists for each of these variables and the parameters of this distribution vary in each environment. Four exposure scenarios have been defined by [Kalliola et al., 2002; Zhao et al., 2002; Olivier, 2008; Vermeeren et al., 2008]: 'Urban Macro-cell', 'Urban Micro-cell', 'Indoor Pico-cell' and 'Outdoor-Indoor'. The 'Rural' scenario is added to this set using propagation models from Kalliola et al. [2002], Zhao et al. [2002], and Asplund et al. [2006]. Table 1 lists the variables, their distributions and the value of their characteristic parameters together with the references to the propagation studies used to determine the parameters. A uniform distribution is chosen for $\alpha$ and $\varphi$ since these parameters depend on the position and orientation of the human body.

Normally every exposure condition requires an FDTD simulation to be carried out. To obtain a distribution of $\mathrm{SAR}_{\mathrm{osa}}$ in a certain environment, several thousands of simulations [Vermeeren et al., 2008, 2012; Iskra, 2011] would have to be performed in order to obtain a stochastic 
representative set of exposure conditions and for every environment a new set of $(>1000)$ simulations would have to be executed. In order to avoid this, a method which reduces the number of FDTD simulations that have to be executed, has been developed in Vermeeren et al. [2008]. As demonstrated in Vermeeren et al. [2008] and Vermeeren et al. [2012], the required number of simulations can be reduced, using the linearity of Maxwell's equations. This linearity allows one to combine different SPW exposure conditions into one exposure condition with multiple plane waves. Therefore, only SPW simulations are needed. As every incident plane wave can be decomposed into two orthogonally polarized plane waves (see Fig. 5), a transverseelectric (TE) and transverse-magnetic (TM) polarized plane wave, SPW exposure conditions only have to be calculated for these 2 polarizations. As is shown in Figure 5 (included in supplementary online materials), the direction of incidence of a plane wave towards the phantom can be described in spherical coordinates, using 2 incident angles: the azimuthal and elevation angles $(\varphi, \theta)$. The ranges for $(\varphi, \theta)$ have been discretized, in order to only perform FDTD simulations for a certain amount of basic incident plane waves. The fields in the phantom's organs induced by this set of incident plane waves are called basic field distributions (BFDs). These can be combined to approximate plane waves coming from any direction [Vermeeren et al., 2008]. Note that using this approach the SAR in a phantom can be estimated in any FF exposure condition using only a finite set of simulations.

Two FDTD simulations with orthogonal incident fields are carried out for every pair $\left(\varphi_{\mathrm{i}}, \theta_{\mathrm{j}}\right)$, where:

$$
\begin{gathered}
\varphi_{i}=i \Delta \varphi \quad i=0,1, \ldots, N_{\varphi} \\
\theta_{j}=j \Delta \theta \quad j=0,1, \ldots, N_{\theta}
\end{gathered}
$$


and

$$
\begin{gathered}
\Delta \varphi=\frac{2 \pi}{N_{\varphi}+1} \\
\Delta \theta=\frac{\pi}{N_{\theta}}
\end{gathered}
$$

$\mathrm{N}_{\varphi}$ and $\mathrm{N}_{\theta}$, the number of steps in $\varphi$ and $\theta$, can be chosen to reduce the interpolation error that occurs when approximating the fields induced in realistic exposure conditions [Vermeeren et al., 2008, 2012]. We extracted $\bar{E}_{T E}\left(\varphi_{i}, \theta_{j}, \bar{r}\right)$ and $\bar{E}_{T M}\left(\varphi_{i}, \theta_{j}, \bar{r}\right)$, the electric fields inside the body induced by a TE or TM polarized plane wave with incident angles $\left(\varphi_{i}, \theta_{j}\right)$, in every grid cell of the organ under consideration. These are the BFDs, which can be combined to approximate a realistic exposure condition. To calculate $\mathrm{SAR}_{\mathrm{osa}}$ values, the volume, density, and conductivity of each grid cell are extracted as well. The volumes are stored in a matrix $V(\bar{r})$, together with the density $\rho(\bar{r})$ and conductivity $\sigma(\bar{r})$.

FF exposure is considered, so the incident EMFs are composed of a set of plane waves. Every plane wave is characterized by its amplitude (A), phase $(\alpha)$, polarization $(\psi)$ and incident azimuth and elevation angles $(\varphi, \theta)$. The resulting electric fields of an exposure sample with $N$ s incident plane waves will then be calculated as:

$$
\bar{E}(\bar{r})=\sum_{l=1}^{N_{S}} A_{j}\left(\sin \psi_{l} \bar{E}_{T E}\left(\varphi_{l}, \theta_{l}, \bar{r}\right)+\cos \psi_{l} \bar{E}_{T M}\left(\varphi_{l}, \theta_{l}, \bar{r}\right)\right) e^{i \alpha_{l}}
$$

In order to determine $\bar{E}_{T E}\left(\varphi_{l}, \theta_{l}, \bar{r}\right)$, noted as $\bar{E}_{T E, l}$, and $\bar{E}_{T M}\left(\varphi_{l}, \theta_{l}, \bar{r}\right)$, noted as $\bar{E}_{T M, l}$, for $\varphi_{l} \in[0,2 \pi]$ and $\theta_{l} \in[0, \pi]$, every plane wave in the set of $N_{S}$ plane waves that compose the realistic exposure condition, is approximated using the extracted BFDs. After obtaining the 
electric fields in every point of the organ from (5), the SAR can be calculated in every point $\bar{r}$ of the organ:

$$
\operatorname{SAR}(\bar{r})=\sigma(\bar{r}) \bar{E}(\bar{r}) \cdot \bar{E}^{*}(\bar{r}) / 2 \rho(\bar{r})
$$

With $\bar{E}(\bar{r})$ the vectorial electric field in each point and $\bar{E}^{*}(\bar{r})$ its complex conjugate. The $\mathrm{SAR}_{\text {osa }}$ is a mass average over the cells of the organ:

$$
S A R_{\text {osa }}=\frac{1}{M_{\text {organ }}} \int_{V_{\text {org }}} \operatorname{SAR}(\bar{r}) m(\bar{r}) d r
$$

As the organ is discretized in space for the FDTD simulations, this becomes:

$$
S A R_{\text {osa }}=\frac{\sum_{k=1}^{N_{\text {cells }}} S A R_{k} V_{k} \rho_{k}}{M_{\text {organ }}}
$$

With $\mathrm{N}_{\text {cells }}$ the number of cells in the organ, $\mathrm{M}_{\text {organ }}$ the organ's mass, $\mathrm{SAR}_{\mathrm{k}}$ the $\mathrm{SAR}$ in grid cell $\mathrm{k}$ of the organ, $\mathrm{V}_{\mathrm{k}}$ the volume of that grid cell, and $\rho_{k}$ its density. The absorbed power can then be calculated from the $\mathrm{SAR}_{\mathrm{osa}}$ :

$$
P_{\text {abs,organ }}=S A R_{\text {osa }} M_{\text {organ }}
$$

In order to get to a $\mathrm{SAR}_{\mathrm{osa}}$ value for a realistic exposure sample $\bar{E}_{T E, l}$ and $\bar{E}_{T M, l}$ in Equation (5) have to be approximated using the BFDs. We propose two methods for this:

\section{Vectorial spline interpolation in every grid cell}

In this first method a cubic spline interpolation is performed over the different $\bar{E}_{T E}\left(\varphi_{i}, \theta_{j}, \bar{r}\right)$ and $\bar{E}_{T M}\left(\varphi_{i}, \theta_{j}, \bar{r}\right)$ to approximate the fields $\bar{E}_{T E}(\varphi, \theta, \bar{r})$ and $\bar{E}_{T M}(\varphi, \theta, \bar{r})$ in each point $\bar{r}$ of the organ under consideration. A different interpolation scheme is used for the two coordinates $\varphi$ and $\theta$. The $\varphi$ coordinate is periodic and extends over a domain that is twice as large as the $\theta$ domain; therefore first an interpolation is performed in this dimension, followed by an interpolation in $\theta$. 
The coefficients for the interpolation in the $\varphi$ direction can be calculated in advance, using a cyclic scheme and using all $\varphi_{i}$ for every $\theta_{j}$. They can thus be stored and loaded whenever necessary, speeding up the calculations. Unfortunately, the coefficients for the interpolation for the $\theta$ coordinate depend on $\varphi$ and cannot be calculated in advance. A cubic spline interpolation using the fields calculated for the 6 nearest $\theta_{j}$ has been chosen. Both interpolations have to be carried out for every vectorial component of the electric field. The advantage of this scheme is its accuracy. The large tensors of interpolation coefficients that have to be loaded in the Randomaccess memory (RAM) are a major disadvantage.

\section{Organ-specific averaged scalar linear interpolation}

While the algorithm described above can very accurately calculate individual $\mathrm{SAR}_{\mathrm{osa}}$ values for a random exposure sample, it provides an accuracy that is unnecessary for a stochastic analysis of

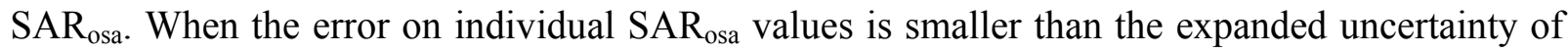
$23 \%$ on SAR values obtained from FDTD simulations using the virtual family [Bakker et al., 2010, 2011a; Vermeeren et al., 2012], it will not influence the $\mathrm{SAR}_{\mathrm{osa}}$ distribution. The method also aims at being accessible for third-party users that normally do not possess the RAM memory required to upload all the BFDs. To generate thousands of samples, which are necessary for the assessment of SAR values in realistic environments [Vermeeren et al., 2008; Iskra et al., 2011], in an appropriate time on a standard desktop computer an alternative faster, but less accurate, method is proposed. The proposed method consists of a linear interpolation between organspecific averaged products between all BFDs.

In this method an organ-specific averaging of the BFDs is performed. This is possible since there only exists a limited number of multiplications between two BFDs in a certain point. When Equation (5) is substituted in (6) and (7), this will lead to: 


$$
\begin{aligned}
S A R_{\text {os }}=\sum_{k=1}^{N_{S}} & \sum_{m=1}^{N_{s}} A_{j} A_{l}\left[\left(\operatorname{Re}\left(S_{1}\right) \gamma-\operatorname{Im}\left(S_{1}\right) \chi\right) \sin \psi_{k} \sin \psi_{m}\right. \\
& +\left(\operatorname{Re}\left(S_{2}\right) \gamma-\operatorname{Im}\left(S_{2}\right) \chi\right) \cos \psi_{k} \cos \psi_{m} \\
& +\left(\operatorname{Re}\left(S_{3}\right) \gamma-\operatorname{Im}\left(S_{3}\right) \chi\right) \cos \psi_{k} \sin \psi_{m} \\
& \left.+\left(\operatorname{Re}\left(S_{3}\right) \gamma+\operatorname{Im}\left(S_{3}\right) \chi\right) \sin \psi_{k} \cos \psi_{m}\right]
\end{aligned}
$$

With $\gamma=\operatorname{Re}\left(e^{\alpha_{k}-\alpha_{m}}\right)$ and $\chi=\operatorname{Im}\left(e^{\alpha_{k}-\alpha_{m}}\right)$. The coefficients $\mathrm{S}_{1}$ to $\mathrm{S}_{3}$ have the following form:

$$
\begin{aligned}
& S_{1}=\frac{1}{M_{\text {organ }}} \int_{V_{\text {org }}} \frac{m \sigma}{2 \rho} \bar{E}_{T E, k} \cdot \bar{E}_{T E, m}^{*} d V \\
& S_{2}=\frac{1}{M_{\text {organ }}} \int_{V_{\text {org }}} \frac{m \sigma}{2 \rho} \bar{E}_{T M, k} \cdot \bar{E}_{T M, m}^{*} d V \\
& S_{3}=\frac{1}{M_{\text {organ }}} \int_{V_{\text {org }}} \frac{m \sigma}{2 \rho} \bar{E}_{T E, k} \cdot \bar{E}_{T M, m}^{*} d V
\end{aligned}
$$

$V_{\text {org }}$ and $M_{\text {organ }}$ are the volume and mass of the studied organ, while $m, \sigma$, and $\rho$ are the mass, conductivity, and density in every grid cell, respectively. The coefficients $\mathrm{S}_{1}-\mathrm{S}_{3}$ can be calculated for every combination of two BFDs, thus for every combination of pairs $\left(\varphi_{i}, \theta_{j}\right)$. These organspecific averaged BFDs (scalars) can then be used for an interpolation in order to determine the coefficients $S_{1}-S_{3}$ for any $(\varphi, \theta)$. A linear interpolation is chosen as it provides a good trade-off between accuracy and execution time. The approximations in this method are: predominantly the use of a linear interpolation and to a smaller extend the fact that the interpolation takes place after the mass averaging, which introduces a larger error than an interpolation of the electric field in every grid cell. The method is considerably faster and has lower memory requirements. Instead of loading $18 \times N_{\varphi} \times N_{\text {cells }}$ data points (the 18 coming from the 3 components of the E field loaded for the 6 nearest $\theta_{\mathrm{j}}$ ) for every exposure sample, now only $6 \times N_{\varphi} \times N_{\theta}$ data points have to be 
loaded. This seriously reduces RAM memory requirements for the user, especially for organs that consist of over one million cells.

\section{RESULTS}

Validation of $S A R_{\text {osa }}$ calculation methods

The goal of our method is to avoid executing an FDTD simulation for every exposure sample. Since the proposed method serves as a substitute for FDTD simulations, the results of the method have to be compared to the results obtained from FDTD simulations. The relative error on $\mathrm{SAR}_{\text {osa }}$ is defined as:

$$
e r r=100 . \frac{\left|S A R_{\text {osa,method }}-S A R_{\text {osa }, F D T D}\right|}{S A R_{\text {osa }, F D T D}}(\%)
$$

The comparison will be made for a number of exposure samples $\left(\mathrm{N}_{\mathrm{smp}}\right)$ in a certain environment, giving rise to an average ( $\left(\mathrm{err}_{\mathrm{av}}\right)$, and maximal $\left(\mathrm{err}_{\mathrm{max}}\right)$ error, as well as a standard deviation (std) on the average error.

Both interpolation schemes will approximate the actual SAR $_{\text {osa }}$ with certain accuracy. To validate the performance of our method the results using an interpolation scheme are compared to the results obtained from 100 FDTD simulated samples in the 'Urban Macro-cell' environment. The electric fields are extracted in all the grid cells of the organs under consideration and SAR osa,FDTD $_{\text {. }}$

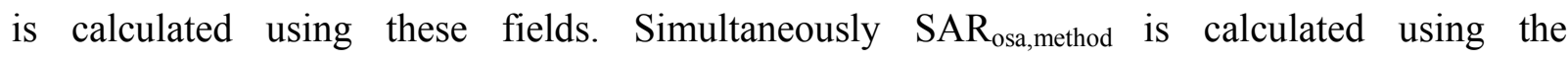
aforementioned methods. Figure 1 shows the $\operatorname{err}_{\mathrm{av}}$ for the cortex of the VFB's kidneys at 950 $\mathrm{MHz}$ for both the vectorial spline (Fig. 1 (a)) and the scalar linear (Fig. 1 (b)) interpolation scheme. Both $\operatorname{err}_{\mathrm{av}}$ are shown for different discretization steps $\Delta \varphi=10^{\circ}-40^{\circ}$ and $\Delta \theta=5^{\circ}-$ $30^{\circ}$. Both interpolation schemes show the expected trend of increased accuracy with decreasing discretization step for the BFDs. The spline interpolation scheme is able to accurately $\left(\operatorname{err}_{\mathrm{av}}<\right.$ 
$1 \%$ ) predict the absorbed power in the kidneys, using $\Delta \varphi=10^{\circ}$ and $\Delta \theta=5^{\circ}$ an $\operatorname{err}_{\mathrm{av}}=0.46 \pm$ $0.42 \%$ is obtained for the cortex of the kidneys. The same discretization step leads to an $\operatorname{err}_{\mathrm{av}}=3.3 \pm 1.5 \%$ for the linear interpolation. For the smallest discretization steps $\left(\Delta \varphi=10^{\circ}\right.$, $\Delta \theta=5^{\circ}$ ) the cell-wise spline interpolation shows an $\operatorname{err}_{\max }=2 \%$ for the kidney's cortex. This $\operatorname{err}_{\max }$ is $6 \%$ for the faster linear interpolation.

Table 2 lists the average errors $\left(\Delta \varphi=10^{\circ}, \Delta \theta=5^{\circ}\right)$ for the different studied organs for the two interpolation methods. The spline interpolation is always more accurate $\left(\operatorname{err}_{\mathrm{av}}<1.8 \%\right.$ ), but is computationally too demanding to be used for all organs. The linear interpolation has a higher average error $\left(\operatorname{err}_{\mathrm{av}}<14.3 \%\right.$ at $\left.\Delta \varphi=10^{\circ}, \Delta \theta=5^{\circ}\right)$.

\section{$S A R_{\text {osa }}$ distributions in realistic environments at $950 \mathrm{MHz}$}

After extracting the BFDs, these are combined to calculate the SAR $\mathrm{osa}_{\mathrm{o}}$ for every sample. To study the $\mathrm{SAR}_{\mathrm{osa}}$ in a realistic environment, a large number of samples have to be taken into consideration, ideally an infinite number of samples. A sample size of 5000 is chosen for every tissue in every environment, providing a good accuracy and an acceptable calculation time per environment. This sample size has been studied for the 'Indoor Pico-cell' scenario and is associated with an average coefficient of variance smaller than $1 \%$ and an average value of the $95 \%$ confidence interval smaller than $6.5 \%$ for percentiles between $0.1 \%$ and $99.9 \%$.

The electric fields incident on the phantom can be normalized using different approaches: using the total incident root mean squared electric field ( $\left.E_{R M S}\right)$, the $E_{R M S}$ averaged over a volume where the phantom should be positioned or the $\mathrm{E}_{\mathrm{RMS}}$ in a point near the phantom. In this study the results are normalized to $E_{\mathrm{RMS}}$ averaged over the volume of a box surrounding the phantom with dimensions $21 \times 37 \times 118 \mathrm{~cm}^{3}$, which are the largest dimensions of the phantom in each orthogonal 
direction. These $\mathrm{E}_{\mathrm{RMS}}$ values are set to the ICNIRP reference level for the incident electric fields at the frequency under consideration [ICNIRP, 1998]. For $950 \mathrm{MHz}$, this is $\mathrm{E}_{\mathrm{RMS}}=42.38 \mathrm{~V} / \mathrm{m}$. Figure 2 (a) shows the cumulative distribution function for the VFB's hypothalamus for 5 different exposure scenarios. There is a dependence of $\mathrm{SAR}_{\mathrm{osa}}$ on the environment. For the VFB's hypothalamus the $\mathrm{SAR}_{\text {osa }}$ values are on average the highest in the 'Urban Macro-cell' scenario, with a mean $\mathrm{SAR}_{\mathrm{osa}}$ value of $0.036 \mathrm{~W} / \mathrm{kg}$, and lowest in the 'Rural' scenario with a mean value of $0.025 \mathrm{~W} / \mathrm{kg}$.

In Figure 2 (b) the percentiles of the cumulative distribution function of the VFB's Hypothalamus in the 'Indoor Pico-cell' are compared for the two proposed methods: the cell-wise spline interpolation and the organ-specific averaged linear interpolation. Every marker on this quantilequantile plot depicts a particular percentile. The $10 \%$ to $90 \%$ percentiles in steps of $10 \%$, complemented with the $0.1 \%, 1 \%, 99 \%$ and $99.9 \%$ percentiles are shown. The vertical axis shows the values of these percentiles using the linear interpolation, while the horizontal axis shows the corresponding values for the spline interpolation. Logarithmic axes are chosen in order to show high $\left(\mathrm{p}_{99.9}\right)$ and low $\left(\mathrm{p}_{0.1}\right)$ percentiles on one figure. Two identical distributions result in a line on the bisector in a quantile-quantile plot, because their percentiles are identical. In Figure 2 (b) the markers follow a line parallel to the bisector (depicted by the linear fit in blue), indicating that both distributions have the same shape (between $\mathrm{p}_{0.1}$ and $\mathrm{p}_{99.9}$ ) but the linear interpolation slightly underestimates the $\mathrm{SAR}_{\mathrm{osa}}$. The same comparison between the two proposed methods is carried out for all studied organs or tissues in all studied environments. For some tissues the linear organ-specific averaged interpolation introduces an overestimation, others show an underestimation. Considering all tissues for which a cell-wise spline interpolation has been executed (listed in Table 2), an average slope of the quantile-quantile plots of 1.02 is found with 
an average offset of $-4 \%$, which is in agreement with Vermeeren et al. [2013]. The linear interpolation thus introduces a small underestimation of $\mathrm{SAR}_{\text {osa }}$, but preserves the shape of the distribution. However, the linear interpolation is an order of magnitude faster than the spline interpolation and requires up to a factor of 200 less memory. The faster linear interpolation is therefore used to obtain the further results presented in this paper.

\section{Comparing $S A R_{\text {osa }}$ in different organs}

Figure 3 shows the mean $\mathrm{SAR}_{\text {osa }}$ and the $90 \%\left(\mathrm{p}_{90}\right)$ and $95 \%\left(\mathrm{p}_{95}\right)$ percentiles of the cumulative distribution function for the different studied organs. Figure 3 (a) shows these values for the VFB's cerebral tissues, while Figure 3 (b) and (c) show the same values for the other studied organs and tissues. As Figure 3 shows, the 'Urban Macro-cell' environment accounts for the highest mean $\mathrm{SAR}_{\mathrm{osa}}$ and $\mathrm{p}_{90}$ and $\mathrm{p}_{95}$ for a majority of the studied organs. The VFB's pancreas generally has the lowest $\mathrm{SAR}_{\mathrm{osa}}$ of the studied organs in all environments, as its mean $\mathrm{SAR}_{\mathrm{osa}}$, $\mathrm{p}_{90}$ and $\mathrm{p}_{95}$ are the lowest in all scenarios $\left(\mathrm{p}_{90} \leq 0.015 \mathrm{~W} / \mathrm{kg}\right.$ and $\left.\mathrm{p}_{95} \leq 0.018 \mathrm{~W} / \mathrm{kg}\right)$. The pancreas has an average conductivity to density ratio $\sigma / \rho$ compared to the other studied organs, but is located relatively deep inside the body compared to the other studied organs. The tongue is the studied organ with the highest mean $\mathrm{SAR}_{\text {osa }}$ in all environments (mean $\mathrm{SAR}_{\mathrm{osa}} \geq 0.11 \mathrm{~W} / \mathrm{kg}$ and $\mathrm{p}_{95} \geq$ $0.21 \mathrm{~W} / \mathrm{kg}$ ). In the 'Rural' and 'Indoor Pico-cell' environments the cornea has the same high mean $\operatorname{SAR}_{\text {osa }}(0.11 \mathrm{~W} / \mathrm{kg})$. The cornea and the penis do show higher $\mathrm{p}_{90}$ and $\mathrm{p}_{95}$ values $\left(\mathrm{p}_{90} \geq 0.21\right.$ $\mathrm{W} / \mathrm{kg}$ and $\mathrm{p}_{95} \geq 0.22 \mathrm{~W} / \mathrm{kg}$ ). The three organs have medium conductivity to density ratios compared to the other studied organs, but are located very close to (tongue) or at the body's surface (cornea, penis). When only considering the cerebral tissues, shown in Figure 3 (a), the 
cerebrospinal fluid has the highest $\mathrm{SAR}_{\mathrm{osa}}$, due to a high $\sigma / \rho$ compared to the other studied organs, while the hypophysis has the lowest mean $\mathrm{SAR}_{\mathrm{osa}}$.

Figure 3 shows that large differences in $\mathrm{SAR}_{\text {osa }}$ can exist between different organs. Several factors will influence the $\mathrm{SAR}_{\mathrm{osa}}$ in realistic environments. Two main contributors are studied in this paragraph: the ratio between the electric conductivity and the density $\sigma / \rho$ and the distance $d$

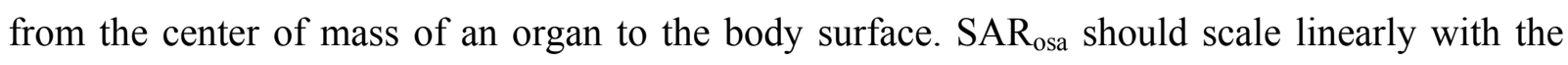
ratio $\sigma / \rho$, due to Equation (6). The internal electric field $(\bar{E}(\bar{r})$ in Equation (6)) should decrease exponentially with the distance in the body, due to the skin effect. However, the distance $\mathrm{d}$ of the center of mass of an organ to the body's surface varies strongly in different directions. This distance is determined in the same directions $\left(\varphi_{i}, \theta_{j}\right)$ (with $\Delta \varphi=10^{\circ}$ and $\Delta \theta=5^{\circ}$ ) as the incident SPWs used for determining the BFDs. These SPWs are incident on the phantom at a field strength equal to the ICNIRP reference levels at $950 \mathrm{MHz}$ and induce a $\mathrm{SAR}_{\mathrm{osa}, \mathrm{SPW}}$ in the studied organs. Note that the $\mathrm{SAR}_{\mathrm{osa}, \mathrm{SPW}}$ induced by these SPWs is not approximated by our method, but a direct result from the performed FDTD simulations. We have determined two distances: $\mathrm{d}_{\text {surf }}(\varphi, \theta)$, the in-body distance to the surface and $\mathrm{d}_{\text {edge }}(\varphi, \theta)$, the distance to the phantom's edge. We consider two distances because it is possible that the line from the center of gravity of a certain organ in direction $(\varphi, \theta)$ intersects with the phantom's surface multiple times, for example if the torso is shielded by an arm in a certain $(\varphi, \theta)$ direction. The distance to the first intersection is $\mathrm{d}_{\text {surf }}(\varphi, \theta)$, while the distance to the last intersection will be $\mathrm{d}_{\text {edge }}(\varphi, \theta)$, this last distance will take into account limbs, the head or the torso that can cause shadowing. Both contributors are investigated using a non-linear regression of their mean values with the mean $\mathrm{SAR}_{\mathrm{osa}, \mathrm{SPW}}$ according to the following model: 


$$
S \hat{\mathrm{A}} R_{\text {osa }}=a_{0}+a_{1} \frac{\sigma}{\rho}+a_{2} e^{-a_{3} d}
$$

Where $\mathrm{d}$ can be the mean $\mathrm{d}_{\text {surf }}$ or $\mathrm{d}_{\text {edge }}$, and $S \hat{A} R_{\text {os }}$ is the estimated value determined by the regression model. The coefficient $\mathrm{a}_{3}$ is included because $\mathrm{d}_{\text {surf }}$ and $\mathrm{d}_{\text {edge }}$ are physical distances and a coefficient is thus needed to model the correct path length in tissue. Table 3 lists the estimates for the coefficients after a regression using all the studied organs and the Pearson correlation between $\mathrm{SAR}_{\mathrm{osa}}$ and the mean $\mathrm{SAR}_{\mathrm{osa}, \mathrm{SPW}}$, together with its p-value. We find good correlations of 0.73 and 0.80 , between our proposed model in Equation (18) and the mean $\mathrm{SAR}_{\mathrm{osa}, \mathrm{SPW}}$.

There are other factors influencing the $\mathrm{SAR}_{\mathrm{osa}}$, e.g., the volume, shape of an organ and dielectric properties of the surrounding tissues. A future study will include these factors and look for a combined regression model.

\section{$S A R_{\text {osa }}$ under single plane-wave exposures}

It is plausible that for a certain organ a quick, worst-case estimation of the exposure can be made using a SPW. The $\mathrm{SAR}_{\mathrm{wb}}$ and peak $\mathrm{SAR}_{10 \mathrm{~g}}$ have been studied deterministically using SPWs incident from the body's main axes [Kühn et al., 2009; Bakker et al., 2010, 2011b]. Moreover the ICNIRP [ICNIRP, 1998] calculates its basic restrictions and reference levels based on SPW exposure. To investigate whether a single plane-wave incident from one of the main axes can be used as a(n) (worst-case) estimation for $\mathrm{SAR}_{\text {osa }}$, we have calculated the $\mathrm{SAR}_{\mathrm{osa}, \mathrm{SPW}}$ values for the organs under consideration in this study for both TE and TM polarization. The six directions of incidence are: from above, beneath, the anterior side, the posterior side and both lateral sides of the phantom. After the proper renormalization the values for the $\mathrm{SAR}_{\mathrm{osa}}$ can be compared to the values that were obtained for the cumulative distribution functions for the different environments. 
Figure 4 shows an example of how these 12 SPW exposure conditions correspond to the cumulative distribution function for the VFB's hypothalamus in the 'Indoor Pico-cell' environment. The TE polarized plane-wave incident from above could be used as a worst case estimation for the hypothalamus $\mathrm{SAR}_{\text {osa }}$, since it is located at the $99 \%$ percentile.

We have extended this plane-wave study to all of the $\left(\varphi_{i}, \theta_{j}\right)$ directions for which we have extracted BFDs. The calculation of $\mathrm{SAR}_{\mathrm{osa}}$ is exact at these angles. Table 4 lists the worst case $\left(\varphi_{i}, \theta_{j}\right)$ (for $\left.\Delta \varphi=10^{\circ}, \Delta \theta=5^{\circ}\right)$ and polarization for every environment and organ, as well as the probability $\mathrm{q}_{\mathrm{SPW}}=\mathrm{P}\left[\mathrm{SAR}_{\mathrm{osa}} \leq \mathrm{SAR}_{\mathrm{osa}, \mathrm{SPW}}\right]$ for this worst-case SPW.

\section{DISCUSSION}

In this study, we demonstrate that we can determine the $\mathrm{SAR}_{\mathrm{osa}}$ for the VFB's organs in five different realistic environments. To this aim we have proposed two methods: a method to calculate the $\mathrm{SAR}_{\mathrm{osa}}$, using a spline interpolation in every grid cell and an organ-specific averaged scalar linear interpolation. The err ${ }_{\mathrm{av}}$ listed in Table 2 demonstrate that both methods are accurate, as the maximal $\operatorname{err}_{\mathrm{av}}$ of $1.8 \%$ (spline int.) and $14.3 \%$ (linear int.) are acceptable, in particular since they are smaller than or comparable to the errors that are associated with FDTD simulations using the Virtual Family: $21 \%$ and $23 \%$ expanded uncorrelated uncertainty $(k=2)$ on $\mathrm{SAR}_{\mathrm{wb}}$ and $\mathrm{SAR}_{10 \mathrm{~g}}$ associated with FDTD simulations [Bakker et al., 2010, 2011a; Vermeeren et al., 2012]. Based on the preferred accuracy and calculation time, a choice has to be made between the different interpolation methods and discretization steps of the incident angles.

The properties (mean value, $\mathrm{p}_{90}$ and $\mathrm{p}_{95}$ ) of $\mathrm{SAR}_{\mathrm{osa}}$ distributions in different environments are shown in Figure 3. An environmental dependence exists for all the studied organs or tissues, although this dependence is relatively small. The maximal difference between the mean $\mathrm{SAR}_{\text {osa }}$ 
value in 2 environments is $46 \%\left(59 \%\right.$ for the $\mathrm{p}_{90}$ and $64 \%$ for the $\left.\mathrm{p}_{95}\right)$, which is small compared to the differences in $\mathrm{SAR}_{\text {osa }}$ that can exist between two distinct organs: a factor of 14.3 between the mean $\mathrm{SAR}_{\mathrm{osa}}$ for the tongue and the pancreas in the Urban Macro-cell environment is the largest difference that occurs. Note that when only studying $\mathrm{SAR}_{\mathrm{wb}}$ or the peak $\mathrm{SAR}_{10 \mathrm{~g}}$ these differences in absorption between different organs, would not become apparent, since only one value would be obtained to describe the absorption in the human body. When the distribution of SAR across the body is of interest, the $\mathrm{SAR}_{\mathrm{osa}}$ obviously provides more information.

A regression model is introduced to explain these differences between $\mathrm{SAR}_{\text {osa }}$ values and provides good correlations using only two factors: the conductivity over density ratio and the distance of an organ's center of gravity to the body's surface and the exterior of the phantom.

A SPW study has been executed for comparison with the existing literature and for a further study of SAR ${ }_{\text {osa. }}$. The results are listed in Table 4 and demonstrate that it is possible to find a SPW for every studied organ that induces an $\mathrm{SAR}_{\text {osa }}$ that is larger than $91 \%$ of the samples in the studied environments. For certain organs (e.g., the VFB's prostate) a dominant path exists and the worst case SPW exposure conditions will exceed all samples in every studied environment. However, not all SPW exposure conditions are realistic and can only be used as a worst-case approximation for a certain environment after comparison with a distribution of multipath exposures.

Table 4 also shows that only for the VFB's epididymis the worst-case SPW condition is one of the 12 incident SPW studied in Kühn et al. [2009] and Bakker et al. [2010, 2011b]. Moreover, the TM polarized SPW with $\varphi=0^{\circ}$ and $\theta=90^{\circ}$, used to establish the ICNIRP guidelines [ICNIRP, 1998], is never found as a worst-case incident SPW for these studied organs. Studying the $\mathrm{SAR}_{\mathrm{osa}}$ deterministically with SPW exposures considering only the SPW incident from the 
phantom's main axis will thus not suffice for a conservative estimation of $\mathrm{SAR}_{\mathrm{osa}}$ and thus the power absorbed in a certain organ.

The dominant polarization is not the same for all organs, while for the $\mathrm{SAR}_{\mathrm{wb}}$ the $\mathrm{TM}$ polarization was considered to be a worst-case SPW exposure [Kühn et al., 2009; Conil et al., 2011; Vermeeren et al., 2012].

The worst-case SPW angles provide more insight in the differences that exist between the SAR ${ }_{\text {osa }}$ distributions for different environments (see Table 1). A majority of the studied organs (87\%) will exhibit their maximal mean $\mathrm{SAR}_{\text {osa }}$ in the environment where the average elevation angle is closest to the worst-case elevation angle, e.g., the kindey's medulla with a worst case $\theta=95^{\circ}$ which exhibits its maximal mean $\mathrm{SAR}_{\text {osa }}$ in the 'Rural' scenario with $\theta_{0}=94^{\circ}$. Another example is shown in Figure 2: the hypothalamus exhibits its highest average $\mathrm{SAR}_{\text {osa }}$ in the 'Urban Macro-cell' scenario, where the average elevation angle is closest to the worst case $\theta=35^{\circ}$. The opposite is also true for the hypothalamus; the average $\mathrm{SAR}_{\text {osa }}$ is lowest in the 'Rural' scenario which has the highest average elevation angle. When the worst-case SPW elevation is closer to the average elevation in a certain environment, it is more likely for this worst-case SPW, and plane wave close to this worst-case SPW, to be part of an exposure sample and thus induce a higher $\mathrm{SAR}_{\text {osa }}$ for the same incident field strength. This will then result in a larger mean $\mathrm{SAR}_{\text {osa }}$.

\section{CONCLUSIONS}

We introduced a method to investigate numerically for the first time the organ-specific averaged SAR $\left(\mathrm{SAR}_{\text {osa }}\right)$ in heterogeneous phantoms in realistic environments. A stochastic method based on a plane-wave approximation of far-field exposure, environmentally dependent distributions for this plane-wave exposure conditions, and the linearity of Maxwell's equations, is extended in 
order to determine SARosa in the Virtual Family Boy at $950 \mathrm{MHz}$. We proposed two different methods, which can both be used to estimate the $\mathrm{SAR}_{\text {osa }}$ for an arbitrary organ and environment. The $\mathrm{SAR}_{\text {osa }}$ can be estimated with an average error lower than $1.8 \%$ using the spline interpolation scheme of basic field distributions with angular resolutions of $10^{\circ}$ in the azimuth angle $\varphi$ and $5^{\circ}$ in the elevation angle $\theta$. Using a linear organ-specific averaged interpolation a maximal average error of $14.3 \%$ can occur. Both methods provide the same shape of the distribution for $\mathrm{SAR}_{\mathrm{osa}}$ in realistic environments. The $\mathrm{SAR}_{\mathrm{osa}}$ in a particular environment has been studied by generating cumulative distribution functions for several organs. These distributions are dependent on the considered organs or tissues and on the studied environment. Both the dielectric properties and the location in the phantom of the studied organ influence the $\mathrm{SAR}_{\text {osa }}$ values. A good correlation using non-linear regression including the conductivity to density ratio $(\sigma / \rho)$ and the location of the center of gravity of the organs with the $\mathrm{SAR}_{\mathrm{osa}}$ has been estimated: 0.73 for the distance to the edge of the phantom and 0.80 for the distance to the surface of the phantom.

Single plane-wave exposures can be used as a worst-case approximation for some of the studied organs at $950 \mathrm{MHz}$ and a single plane-wave exposure condition exceeding $91 \%$ of the exposure samples could be found for all studied organs. The polarization of this worst-case single planewave exposure is dependent on the considered organ.

The future research will consist of extending the proposed method to other frequencies and phantoms. A further analysis of the factors influencing the $\mathrm{SAR}_{\text {osa }}$ will be executed and recent propagation models for the incident fields will be implemented in the future. A method to determine the actual polarization and incident angles of the worst-case single plane wave is also under development. 


\section{ACKNOWLEDGEMENTS}

Wout Joseph is a Post-Doctoral Fellow of the FWO-V. 


\section{REFERENCES}

Aydin D, Feychting M, Schüz J, Tynes T, Andersen TV, Schmidt LS, Poulsen AH, Johansen C, Prochazka M, Lannering B, Klæboe L, Eggen T, Jenni D, Grotzer M, Von der Weid N, Kuehni C E, Röösli M. 2011. Mobile Phone Use and Brain Tumors in Children and Adolescents: A Multicenter Case-Control Study. J Natl Cancer Inst 103:1264-1276.

Bakker JF, Paulides MM, Christ A, Kuster N, van Rhoon GC. 2010. Assessment of induced SAR in children exposed to electromagnetic plane waves between $10 \mathrm{MHz}$ and $5.6 \mathrm{GHz}$. Phys Med Biol 55(11): 3115-3130.

Bakker JF, Paulides MM, Christ A, Kuster N, van Rhoon GC. 2011a. Corrigendum: Assessment of induced SAR in children exposed to electromagnetic plane waves between $10 \mathrm{MHz}$ and 5.6 GHz. Phys Med Biol 56: 2883.

Bakker JF, Paulides MM, Neufeld E, Christ A, Kuster N, van Rhoon GC. 2011b. Children and adults exposed to electromagnetic fields at the ICNIRP reference levels: theoretical assessment of the induced peek temperature increase. Phys Med Biol 56: $4967-4989$.

Baste V, Riise T, Moen BE. Radiofrequency electromagnetic fields; male infertility and sex ratio of offspring. 2008. Eur J Epidemiol 23:369-377. 
Bernardi P, Cavagnaro M, Pisa S, Piuzzi E. 2000. Human exposure to radio base-station antennas in urban environment, Trans Microw Theory Tech 48: 1996-2002.

Christ A, Samaras T, Klingenböck A, Küster N. 2006. Characterization of the electromagnetic near-field absorption in layered biological tissue in the frequency range from $30 \mathrm{MHz}$ to 6000 MHz. Phys Med Biol 51:4951-4965.

Christ A, Gosselin MC, Christopoulou M, Kühn S, Kuster N. 2010a. Age-dependent tissuespecific exposure of cell phone users. Phys Med Biol 55: 1767-1783.

Christ A, Kainz W, Hahn EG, Honegger K, Zefferer M, Neufeld E, Rascher W, Janka R, Bautz W, Chen J, Kiefer B, Schmitt P, Hollenbach H, Shen J, Oberle M, Szczerba D, Kam A, Guag JW, Kuster N. 2010b. The Virtual Family, development of surface-based anatomical models of two adults and two children for dosimetric simulations. Phys Med Biol 55: N23-38.

Conil E, Hadjem A, Lacroux F, Wong MF, Wiart J. 2011. Influence of plane-wave incidence angle on whole body and local exposure at $2100 \mathrm{MHz}$. IEEE Transactions on Electromagnetic Compatibility 53 (1): 48-52.

Crespo-Valero P, Christopoulou M, Zefferer M, Christ A, Achermann P, Nikita KS, Kuster N. 2011. Novel methodology to characterize electromagnetic exposure of the brain. Phys Med Biol 56: 383-396. 
Dimbylow PJ, Nagaoka T, Xu X G. 2009. A comparison of foetal SAR in three sets of pregnant female models. Phys Med Biol 54: 2755 - 2767.

Dimbylow PJ, Bolch W, Lee C. 2010. SAR calculations from $20 \mathrm{MHz}$ to $6 \mathrm{GHz}$ in the University of Florida newborn voxel phantom and their implications for dosimetry. Phys Med Biol 55: 1519 $-1530$.

Findlay RP, Dimbylow PJ. 2008. Calculated SAR distributions in a human voxel phantom due to the reflection of electromagnetic fields from a ground plane between $65 \mathrm{MHz}$ and $2 \mathrm{GHz}$. Phys Med Biol 53: 2277-2289.

Findlay RP, Lee A-K, Dimbylow P J. 2009. FDTD calculations of SAR for child voxel models in different postures between $10 \mathrm{MHz}$ and $3 \mathrm{GHz}$. Radiation Protection Dosimetry 135 (4): $226-231$.

Gabriel S, Lau RW, Gabriel C. 1996. The dielectric properties of biological tissues: III. Parametric models for the dielectric spectrum of tissues. Phys Med Biol 41: 2271-2293.

Hand JW. 2008. Modelling the interaction of electromagnetic fields (10 MHz-10 GHz) with the human body: methods and applications. Phys Med Biol 53: R243-R286. 
Hirata A, Kodera S, Wang J, Fujiwara O. 2007. Dominant factors influencing whole-body average SAR due to far-field exposure in whole-body resonance frequency and $\mathrm{GHz}$ regions. Bioelectromagnetics 28: $484-487$.

Hirata A, Ito N, Fujiwara O. 2009. Influence of electromagnetic polarization on the whole-body averaged SAR in children for plane-wave exposures. Phys Med Biol 54: N59 - N65.

Huber R, Schuderer J, Graf T, Jütz K, Borbély AA, Kuster N, Achermann P. 2003. Radio frequency electromagnetic field exposure in humans: estimation of SAR distribution in the brain, effects on sleep and heart rate. Bioelectromagnetics 24: 262-276.

Institute of Electrical and Electronics Engineers, 2005. IEEE Standard for safety levels with respect to human exposure to radio frequency electromagnetic fields, $3 \mathrm{kHz}$ to $300 \mathrm{GHz} \mathrm{Std}$ C95.1 New York: IEEE.

International Commission on Non-Ionizing Radiation Protection. 1998. Guidelines for limiting exposure to time-varying electric, magnetic, and electromagnetic fields (up to $300 \mathrm{GHz}$ ). Health Physics 74: 494-522.

The INTERPHONE Study Group. 2010. Brain tumour risk in relation to mobile telephone use: results of the INTERPHONE international case-control study. Int J Epidemiol 39: 675-694. 
Iskra S, McKenzie R, Cosic I. 2011. Monte Carlo simulations of the electric field close to the body in realistic environments for application in personal radiofrequency dosimetry. Radiat Prot Dosimetry 147(4): 517-527.

Kalliola K, Sulonen K, Laitinen H, Kivekäs O, Krogerus J, Vainikainen P. 2002. Angular power distribution and mean effective Gain of mobile antenna in different propagation environments. IEEE transactions on vehicular technology 51 (5): 823-838.

Kühn S, Jennings W, Christ A, Kuster N. 2009. Assessment of induced radio-frequency electromagnetic fields in various anatomical human body models. Phys Med Biol 54: 875 - 890 .

Larjavaara S, Schüz J, Swerdlow A, Feychting M, Johansen C, Lagorio S, Tynes T, Klaeboe L, Tonjer SR, Blettner M, Berg-Beckhoff G, Schlehofer B, Schoemaker M, Britton J, Mäntylä R, Lönn S, Ahlbom A, Flodmark O, Lilja A, Martini S, Rastelli E, Vidiri A, Kähärä V, Raitanen J, Heinävaara S, Auvinen A. 2011. Location of gliomas in relation to mobile telephone use: A casecase and case-specular analysis. Am J Epidemiol 174(1): 2-11.

Olivier C. 2007. Characterisation of the Electromagnetic Radiation Close to Broadcast and Wireless Communications Antennas. PhD thesis, Ghent University, Ghent, Belgium.

Regel SJ, Tinguely G, Schuderer J, Adam M, Kuster N, Landolt H-P, Achermann P. 2007. Pulsed radio-frequency electromagnetic fields: dose-dependent effects on sleep, the sleep EEG and cognitive performance. J Sleep Res 16: 253-258. 
Uusitupa T, Laakso I, Ilvonen S, Nikoskinen K. 2010. SAR variation study from 300 to 5000 MHz for 15 voxel models including different postures. Phys Med Biol 55: $1157-1176$.

Valentini E, Curcio G, Moroni F, Ferrara M, De Gennaro L, Bertini M. 2007. Neurophysiological effects of mobile phone electromagnetic fields on humans: a comprehensive review. Bioelectromagnetics 28:415-432.

Vermeeren G, Joseph W, Olivier C, Martens L. 2008. Statistical multipath exposure of a human in a realistic electromagnetic environment, Health Physics 94: 345 - 354.

Vermeeren G, Joseph W, Martens L. 2013. Statistical multi-path exposure method for assessing the whole-body SAR in a heterogeneous human body model in a realistic environment. Bioelectromagnetics 34 (3): 240-251.

Zhao X, Kivinen J, Vainikainen P, Skog K. 2002. Propagation characteristics for wideband outdoor mobile communications at $5.3 \mathrm{GHz}$. IEEE Journal on Selected Areas in Communications 20 (3): 507-514. 


\section{List of captions}

Table 1: Variables of the used exposure scenarios and the distributions that characterize them. Partly taken from [Olivier, 2007].

Table 2: $\operatorname{Err}_{\mathrm{av}} \pm$ std (\%) using the two interpolation schemes for the vhf boy's organs in different exposure scenarios.

Table 3: Coefficients, correlation coefficients (r), and the p-value for these correlation coefficients for the fit using Equation (19).

Table 4: Worst-case single plane-wave exposure with incident field strength $E_{\mathrm{RMS}}=42.38 \mathrm{~V} / \mathrm{m}$, for every organ. The corresponding incident angles, polarization and $\mathrm{q}_{\mathrm{SPW}}=\mathrm{P}\left[\mathrm{SAR}_{\mathrm{osa}} \leq \mathrm{SAR}_{\mathrm{osa}, \mathrm{SPW}}\right]$ in every environment are listed.

Figure 1: $\operatorname{err}_{\mathrm{av}}$ on the $\mathrm{SAR}_{\mathrm{osa}}$ in the cortex of the VFB's kidney at $950 \mathrm{MHz}$ for 100 samples. (a) $\operatorname{err}_{\mathrm{av}}$ using spline interpolation, (b) err $\mathrm{av}_{\mathrm{av}}$ using linear interpolation.

Figure 2: (a) Cumulative distribution function for different exposure conditions averaged over a box surrounding the phantom at $950 \mathrm{MHz}$ for the VFB's hypothalamus using the spline interpolation. (b) Quantile-quantile plot from the $0.1 \%$ till the $99.9 \%$ percentile, comparing both $\mathrm{SAR}_{\text {osa }}$ calculating methods for the VFB's hypothalamus in the Indoor Pico-cell environment.

Figure 3: Mean $\mathrm{SAR}_{\text {osa }}$, and the 90 , and $95 \% \mathrm{SAR}_{\mathrm{osa}}-$ percentiles $(\mathrm{W} / \mathrm{kg})$ normalized over a box (volume) surrounding the phantom with dimensions $21 \times 37 \times 118 \mathrm{~cm}^{3}$, for different exposure scenarios. For every organ the five columns represent the different environments. The three divisions in each column indicate the values that are lower than the mean $\mathrm{SAR}_{\mathrm{osa}}$ and the values that are lower than 90 and $95 \%$ of the studied samples in each environment. (a) Cerebral regions 
in descending order of the maximal $p_{95} .(b)$ and (c) Other studied tissues in descending order of the maximal $\mathrm{p}_{95}$.

Figure 4: Cumulative distribution function for the 'Indoor Pico-cell' environment, averaged over a box surrounding the phantom at $950 \mathrm{MHz}$ for the VFB's hypothalamus, including $12 \mathrm{SPW}$ incident from the phantom's main axis. 


\begin{tabular}{|c|c|c|c|c|c|}
\hline Scenario & $\begin{array}{c}\text { Urban } \\
\text { Macro-cell }\end{array}$ & $\begin{array}{l}\text { Urban } \\
\text { Micro-cell }\end{array}$ & $\begin{array}{c}\text { Indoor } \\
\text { Pico-cell }\end{array}$ & $\begin{array}{l}\text { Outdoor- } \\
\text { Indoor }\end{array}$ & Rural \\
\hline \multicolumn{6}{|l|}{ Elevation $(\boldsymbol{\theta})$ [Kalliola et al., 2002] } \\
\hline \multicolumn{6}{|l|}{$\begin{array}{c}\text { Asymmetric Double exponential } \\
\text { distribution }\end{array}$} \\
\hline Peak elevation angle: $\theta_{0}\left({ }^{\circ}\right)$ & 87.8 & 88.0 & 88.0 & 90.2 & 94.0 \\
\hline Spread parameter $\theta \in\left[0, \theta_{0}\right]: \sigma^{-}\left(^{\circ}\right)$ & 3.9 & 4.3 & 6.9 & 5.4 & 8.0 \\
\hline Spread parameter $\theta \in\left[\theta_{0}, \pi\right]: \sigma^{+}\left(^{\circ}\right)$ & 17.8 & 8.2 & 9.4 & 5.5 & 5.7 \\
\hline \multicolumn{6}{|l|}{ Polarization $(\psi)$ [Kalliola et al., 2002] } \\
\hline \multicolumn{6}{|l|}{ Gaussian distribution } \\
\hline Cross Polarization Ratio (dB) & 7.3 & 11.1 & 7.0 & 10.7 & 6.6 \\
\hline \multicolumn{6}{|l|}{ Nr of Paths $\left(\mathbf{N}_{\mathrm{S}}\right)$ [Zhao et al., 2002] } \\
\hline \multicolumn{6}{|l|}{ Gao distribution } \\
\hline Maximum number of paths: $\mathrm{N}_{\mathrm{T}}$ & 22 & 14 & 16 & 21 & 9 \\
\hline Distribution parameter: $\eta$ & 2.7 & 3.5 & 4.7 & 4.5 & 4.0 \\
\hline \multicolumn{6}{|l|}{$\begin{array}{l}\text { Magnitude E field (A), Shadowing } \\
\text { [Asplund et al., 2006; Olivier, 2007] }\end{array}$} \\
\hline \multicolumn{6}{|l|}{ Lognormal distribution } \\
\hline Standard deviation $\sigma_{E}(d B)$ & 6 & 9 & 6 & 12 & 6 \\
\hline
\end{tabular}

Table 1 


\begin{tabular}{|c|c|c|}
\hline Organ/Tissue & $\begin{array}{l}\text { Spline interpolation }^{1} \\
e r r_{a v} \pm s t d(\%)\end{array}$ & $\begin{array}{l}\text { Linear interpolation } \\
e r r_{a v} \pm s t d(\%)\end{array}$ \\
\hline Adrenal gland & $1.8 \pm 1.6$ & $4.3 \pm 2.3$ \\
\hline Artery & & $6.6 \pm 2.0$ \\
\hline Bladder & & $2.1 \pm 1.6$ \\
\hline Brain grey matter & & $14.0 \pm 4.5$ \\
\hline Brain white matter & & $14.0 \pm 4.5$ \\
\hline Cerebellum & & $11.7 \pm 4.1$ \\
\hline Cerebrospinal fluid & $0.26 \pm 0.15$ & $12.9 \pm 4.1$ \\
\hline Commissura anterior & $0.57 \pm 0.61$ & $12.7 \pm 5.1$ \\
\hline Cornea & $0.40 \pm 0.55$ & $11.4 \pm 4.1$ \\
\hline Epididymis & $0.56 \pm 0.56$ & $1.9 \pm 1.7$ \\
\hline Eye lens & $0.34 \pm 0.47$ & $11.3 \pm 4.0$ \\
\hline Eye sclera & $0.30 \pm 0.40$ & $11.4 \pm 4.0$ \\
\hline Eye vitreous humor & $0.27 \pm 0.35$ & $11.4 \pm 4.1$ \\
\hline Gallbladder & & $3.1 \pm 2.3$ \\
\hline Heart lumen & & $4.3 \pm 2.3$ \\
\hline Heart muscle & & $5.5 \pm 2.3$ \\
\hline Hippocampus & $0.64 \pm 0.47$ & $13.3 \pm 4.6$ \\
\hline Hypophysis & $1.10 \pm 1.07$ & $10.4 \pm 4.2$ \\
\hline Hypothalamus & $0.60 \pm 0.54$ & $12.3 \pm 4.7$ \\
\hline Kidney cortex & $0.46 \pm 0.42$ & $3.3 \pm 1.5$ \\
\hline Kidney medulla & $0.71 \pm 0.79$ & $3.8 \pm 2.1$ \\
\hline Liver & & $3.7 \pm 1.6$ \\
\hline Lung & & $6.4 \pm 2.0$ \\
\hline Medulla oblongata & $1.0 \pm 0.95$ & $10.5 \pm 3.9$ \\
\hline Midbrain & $0.46 \pm 0.41$ & $13.5 \pm 4.5$ \\
\hline Nerve & $0.55 \pm 0.55$ & $5.6 \pm 2.8$ \\
\hline Pancreas & & $2.8 \pm 2.0$ \\
\hline Penis & $0.42 \pm 0.42$ & $1.7 \pm 1.7$ \\
\hline Pineal body & $0.53 \pm 0.45$ & $14.3 \pm 5.0$ \\
\hline
\end{tabular}




$\begin{array}{ccc}\text { Pons } & 0.65 \pm 0.52 & 11.7 \pm 4.1 \\ \text { Prostate } & 0.90 \pm 0.92 & 2.5 \pm 2.2 \\ \text { Spinal cord } & & 7.6 \pm 3.1 \\ \text { Spleen } & & 4.0 \pm 1.9 \\ \text { Testis } & 0.44 \pm 0.68 & 1.7 \pm 2.0 \\ \text { Thalamus } & 0.38 \pm 0.30 & 14.0 \pm 4.5 \\ \text { Thymus } & & 6.9 \pm 2.9 \\ \text { Tongue } & & 8.8 \pm 3.2 \\ \text { Vein } & & 6.1 \pm 1.8\end{array}$

${ }^{1}$ This error has not been estimated for all tissues due to high memory requirements

Table 2 


\begin{tabular}{ccccccc}
\hline Distance & $\mathrm{a}_{0}(\mathrm{~W} / \mathrm{kg})$ & $\mathrm{a}_{1}\left(\mathrm{~V}^{2} / \mathrm{m}^{2}\right)$ & $\mathrm{a}_{2}(\mathrm{~W} / \mathrm{kg})$ & $\mathrm{a}_{3}\left(\mathrm{~m}^{-1}\right)$ & $\mathbf{r}$ & $\mathbf{p}$ \\
\hline $\mathbf{d}_{\text {surf,mean }}$ & -0.02 & 34 & 0.37 & 26 & $\mathbf{0 . 8 0}$ & $\mathbf{1 . 5} \times \mathbf{1 0}^{-9}$ \\
d $_{\text {edge,mean }}$ & -0.03 & 35 & 0.40 & 18 & $\mathbf{0 . 7 3}$ & $\mathbf{1 . 8 \times \mathbf { 1 0 } ^ { - 7 }}$ \\
\hline
\end{tabular}

Table 3 


\begin{tabular}{|c|c|c|c|c|c|c|c|}
\hline Scenario & & & Urban & & & & Rural \\
\hline Organ & $\left(\varphi_{i}, \theta_{j}\right)\left(^{\circ}\right)$ & Pol & $\mathrm{q}_{\mathrm{SPW}}$ & qSPW & $\mathrm{q}_{\mathrm{SPW}}$ & qSPW & qSPW \\
\hline Adrenal gland & $(210,115)$ & $\mathrm{TM}$ & 0.988 & 0.991 & 0.989 & 0.991 & 0.993 \\
\hline Artery & $(0,105)$ & $\mathrm{TM}$ & 0.988 & 0.986 & 0.987 & 0.988 & 0.992 \\
\hline Bladder & $(0,80)$ & $\mathrm{TM}$ & 0.979 & 0.987 & 0.986 & 0.991 & 0.991 \\
\hline $\begin{array}{l}\text { Brain grey } \\
\text { matter }\end{array}$ & $(350,25)$ & $\mathrm{TM}$ & 0.933 & 0.976 & 0.968 & 0.981 & 0.984 \\
\hline $\begin{array}{l}\text { Brain white } \\
\text { matter }\end{array}$ & $(340,25)$ & $\mathrm{TM}$ & 0.914 & 0.958 & 0.957 & 0.975 & 0.983 \\
\hline Cerebellum & $(180,120)$ & $\mathrm{TM}$ & 0.986 & 0.987 & 0.988 & 0.983 & 0.984 \\
\hline $\begin{array}{l}\text { Cerebrospinal } \\
\text { fluid }\end{array}$ & $(0,25)$ & $\mathrm{TM}$ & 0.938 & 0.965 & 0.969 & 0.980 & 0.982 \\
\hline $\begin{array}{l}\text { Commissura } \\
\text { anterior }\end{array}$ & $(0,80)$ & $\mathrm{TM}$ & 0.954 & 0.976 & 0.980 & 0.985 & 0.990 \\
\hline Cornea & $(350,80)$ & $\mathrm{TM}$ & 0.977 & 0.986 & 0.987 & 0.992 & 0.994 \\
\hline Epididymis & $(0,90)$ & $\mathrm{TE}$ & 1 & 1 & 1 & 1 & 1 \\
\hline Eye lens & $(350,80)$ & $\mathrm{TM}$ & 0.975 & 0.983 & 0.986 & 0.989 & 0.993 \\
\hline Eye sclera & $(0,60)$ & $\mathrm{TM}$ & 0.972 & 0.985 & 0.986 & 0.990 & 0.993 \\
\hline $\begin{array}{l}\text { Eye vitreous } \\
\text { humor }\end{array}$ & $(0,80)$ & $\mathrm{TM}$ & 0.973 & 0.984 & 0.987 & 0.989 & 0.994 \\
\hline Gallbladder & $(340,100)$ & $\mathrm{TM}$ & 0.988 & 0.991 & 0.990 & 0.989 & 0.987 \\
\hline Heart lumen & $(0,85)$ & $\mathrm{TM}$ & 0.961 & 0.975 & 0.976 & 0.980 & 0.988 \\
\hline Heart muscle & $(0,75)$ & $\mathrm{TM}$ & 0.970 & 0.980 & 0.984 & 0.986 & 0.991 \\
\hline Hippocampus & $(300,85)$ & $\mathrm{TE}$ & 0.982 & 0.995 & 0.993 & 0.996 & 0.998 \\
\hline Hypophysis & $(350,40)$ & $\mathrm{TM}$ & 0.987 & 0.998 & 0.998 & 0.999 & 1 \\
\hline Hypothalamus & $(0,35)$ & $\mathrm{TM}$ & 0.997 & 0.998 & 0.999 & 0.999 & 0.999 \\
\hline Kidney cortex & $(180,105)$ & $\mathrm{TM}$ & 0.986 & 0.984 & 0.982 & 0.984 & 0.987 \\
\hline Kidney medulla & $(180,95)$ & $\mathrm{TE}$ & 0.986 & 0.984 & 0.980 & 0.985 & 0.982 \\
\hline Liver & $(340,90)$ & $\mathrm{TE}$ & 0.996 & 0.998 & 0.998 & 0.999 & 0.997 \\
\hline Lung & $(210,80)$ & $\mathrm{TE}$ & 0.984 & 0.989 & 0.989 & 0.995 & 0.997 \\
\hline Medulla & $(90,65)$ & $\mathrm{TM}$ & 0.935 & 0.958 & 0.959 & 0.964 & 0.969 \\
\hline
\end{tabular}




\begin{tabular}{cccccccc} 
oblongata & & & & & & \\
Midbrain & $(170,10)$ & TE & 0.977 & 0.991 & 0.995 & 0.997 & 0.999 \\
Nerve & $(180,60)$ & TM & 0.966 & 0.979 & 0.976 & 0.981 & 0.986 \\
Pancreas & $(330,100)$ & TM & 0.986 & 0.991 & 0.988 & 0.987 & 0.981 \\
Penis & $(0,45)$ & TM & 0.989 & 0.997 & 0.996 & 0.998 & 0.998 \\
Pineal body & $(80,20)$ & TE & 0.997 & 0.999 & 0.999 & 0.999 & 1 \\
Pons & $(180,75)$ & TM & 0.968 & 0.980 & 0.980 & 0.987 & 0.992 \\
Prostate & $(0,100)$ & TE & 1 & 1 & 1 & 1 & 1 \\
Spinal cord & $(180,80)$ & TM & 0.970 & 0.978 & 0.977 & 0.986 & 0.990 \\
Spleen & $(160,95)$ & TE & 0.991 & 0.992 & 0.992 & 0.993 & 0.992 \\
Testis & $(0,105)$ & TM & 0.990 & 0.995 & 0.995 & 0.996 & 0.995 \\
Thalamus & $(180,80)$ & TE & 0.995 & 0.999 & 0.998 & 0.999 & 1 \\
Thymus & $(0,85)$ & TM & 0.971 & 0.980 & 0.983 & 0.985 & 0.992 \\
Tongue & $(0,105)$ & TM & 0.974 & 0.981 & 0.982 & 0.984 & 0.987 \\
Vein & $(0,115)$ & TM & 0.969 & 0.966 & 0.970 & 0.962 & 0.979 \\
\hline
\end{tabular}

Table 4 


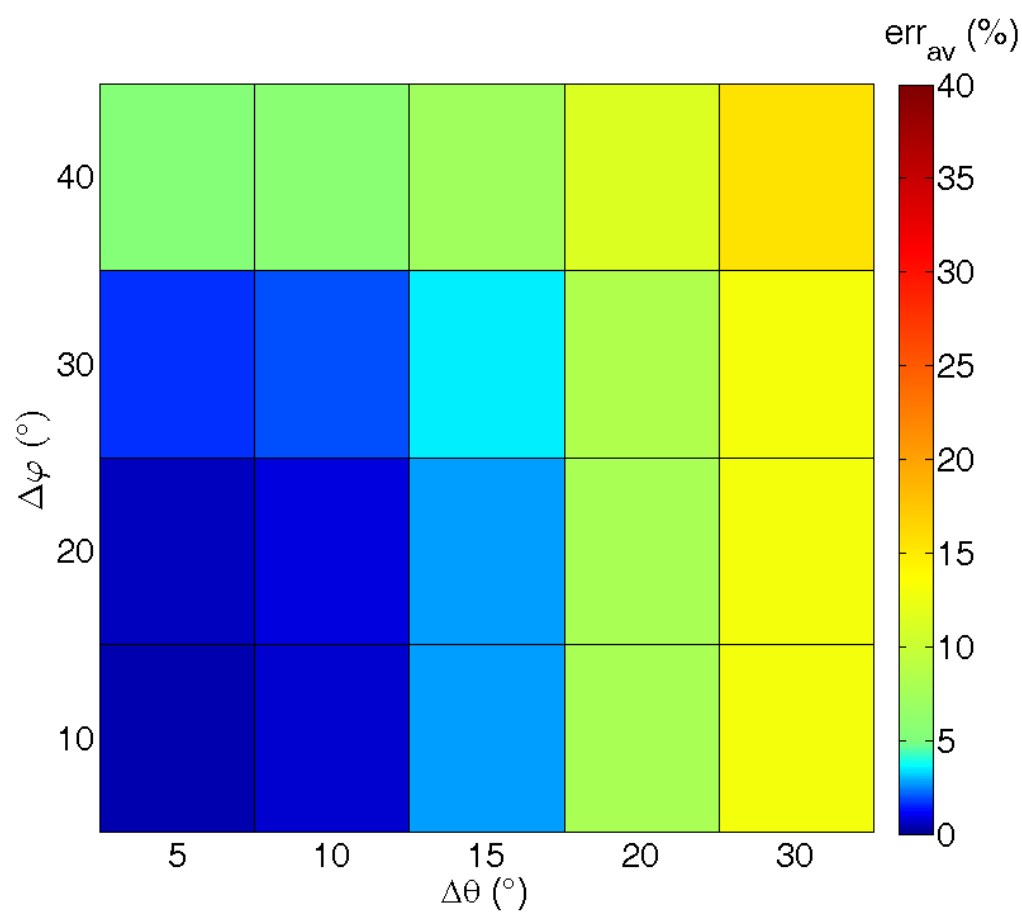

(a)

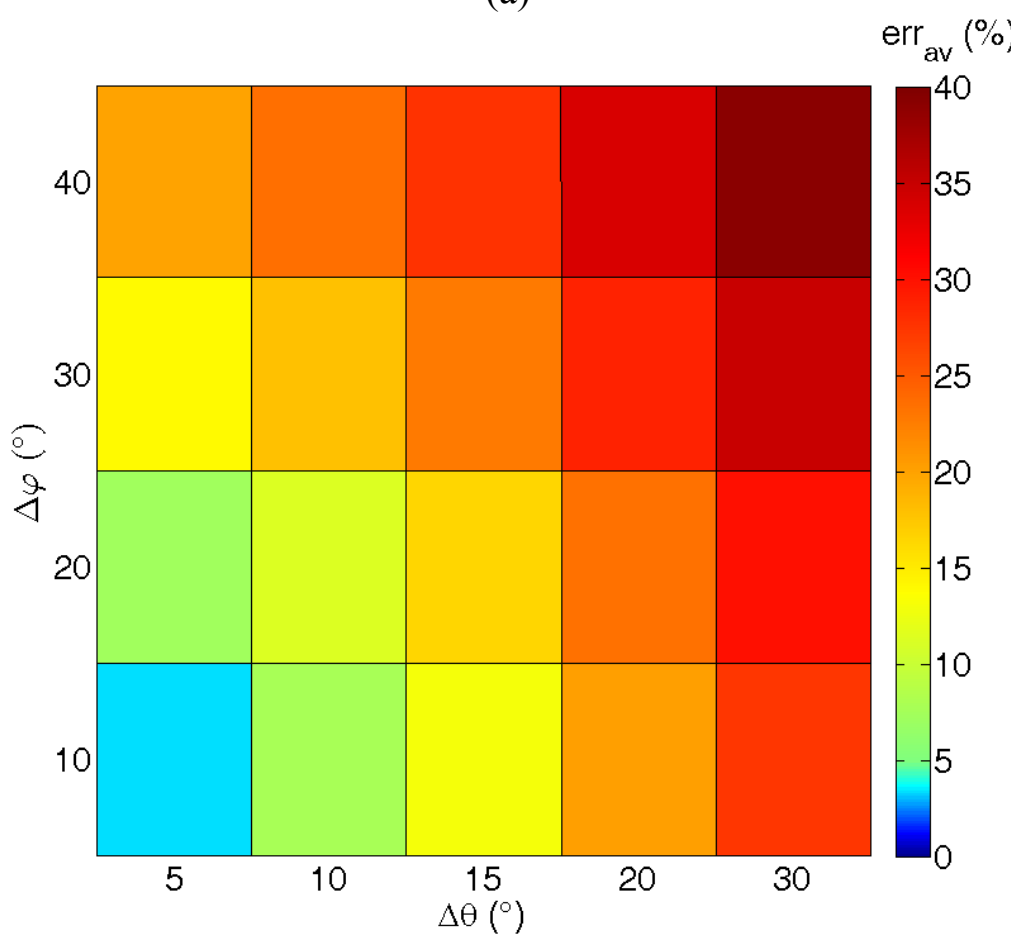

(b)

Figure 1 


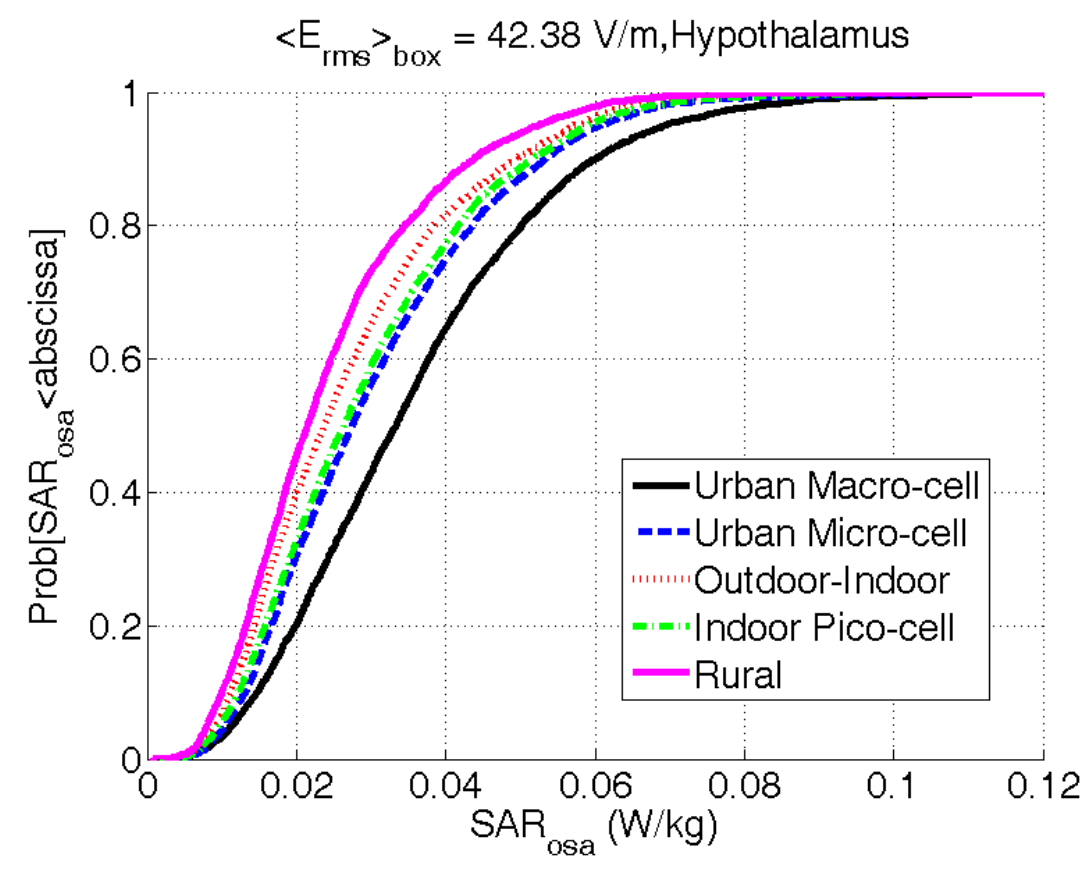

(a)

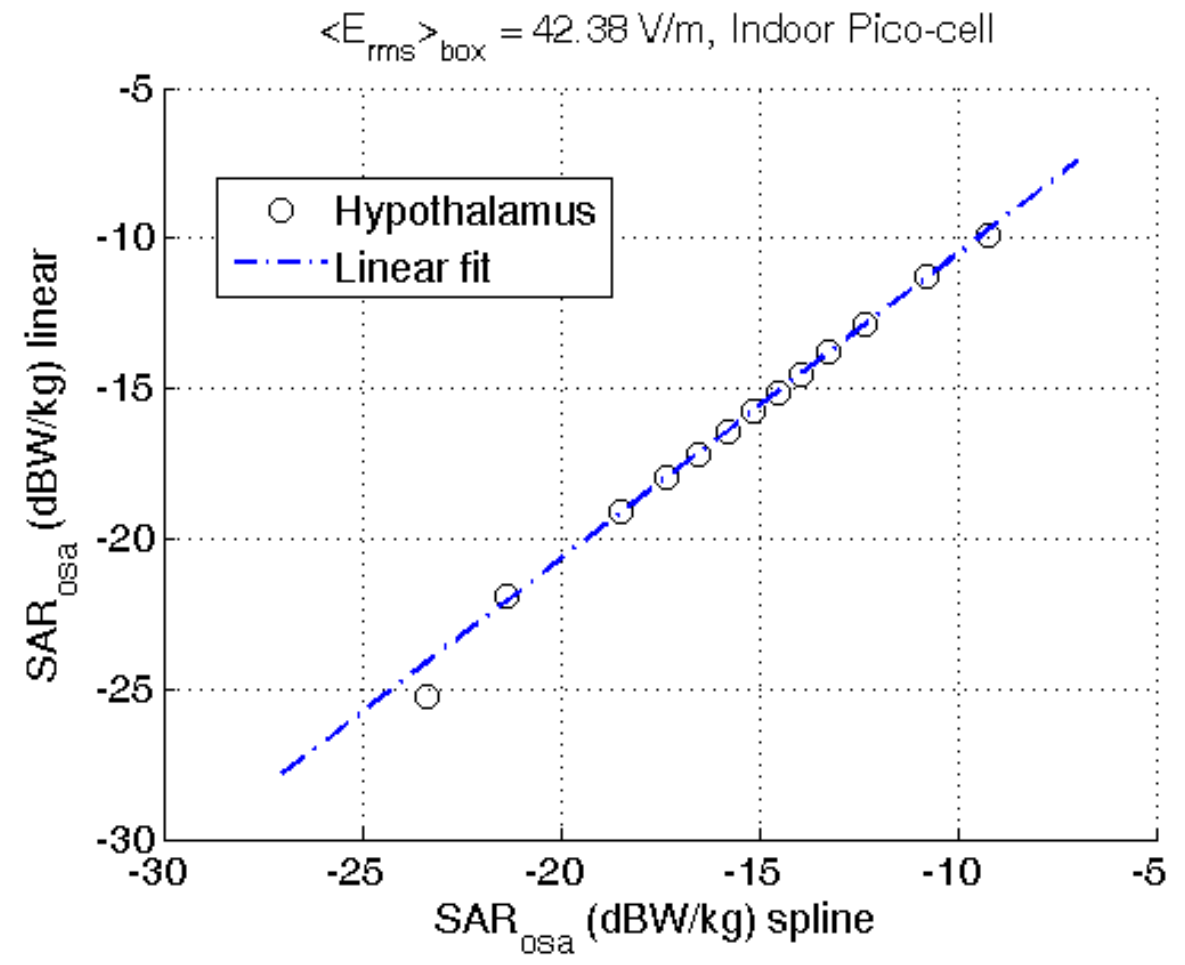

(b)

Figure 2 


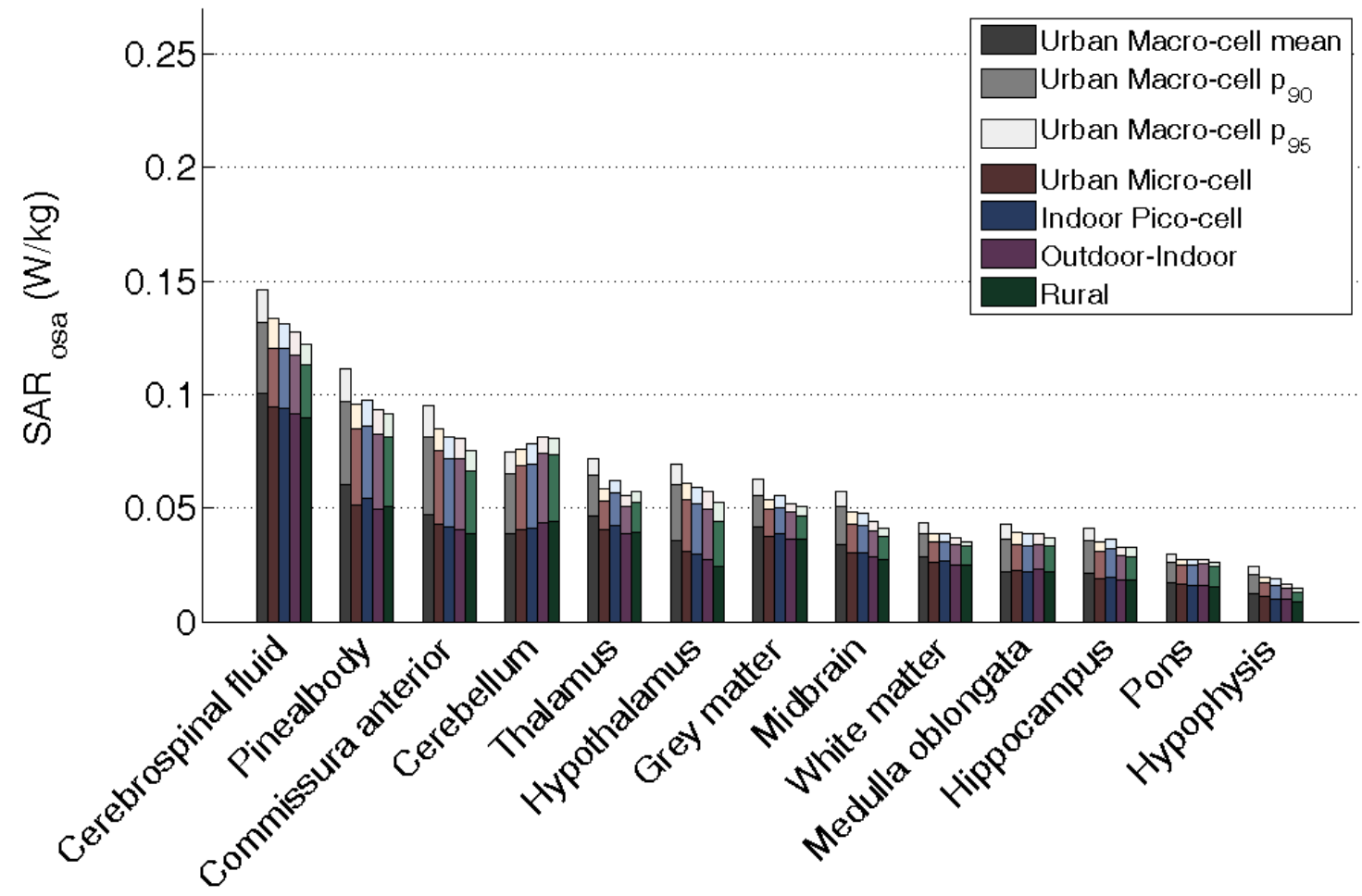

(a)

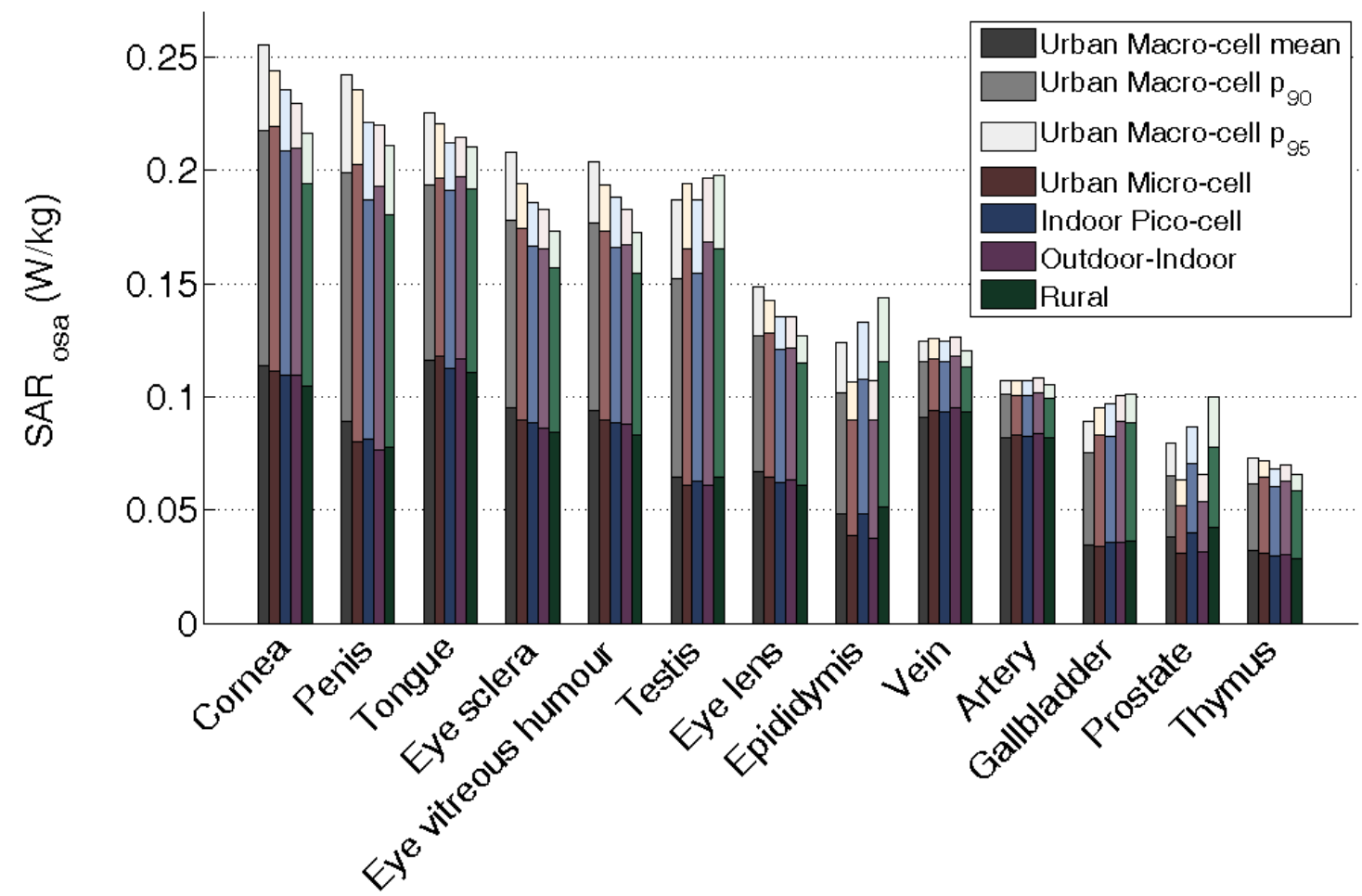

(b) 


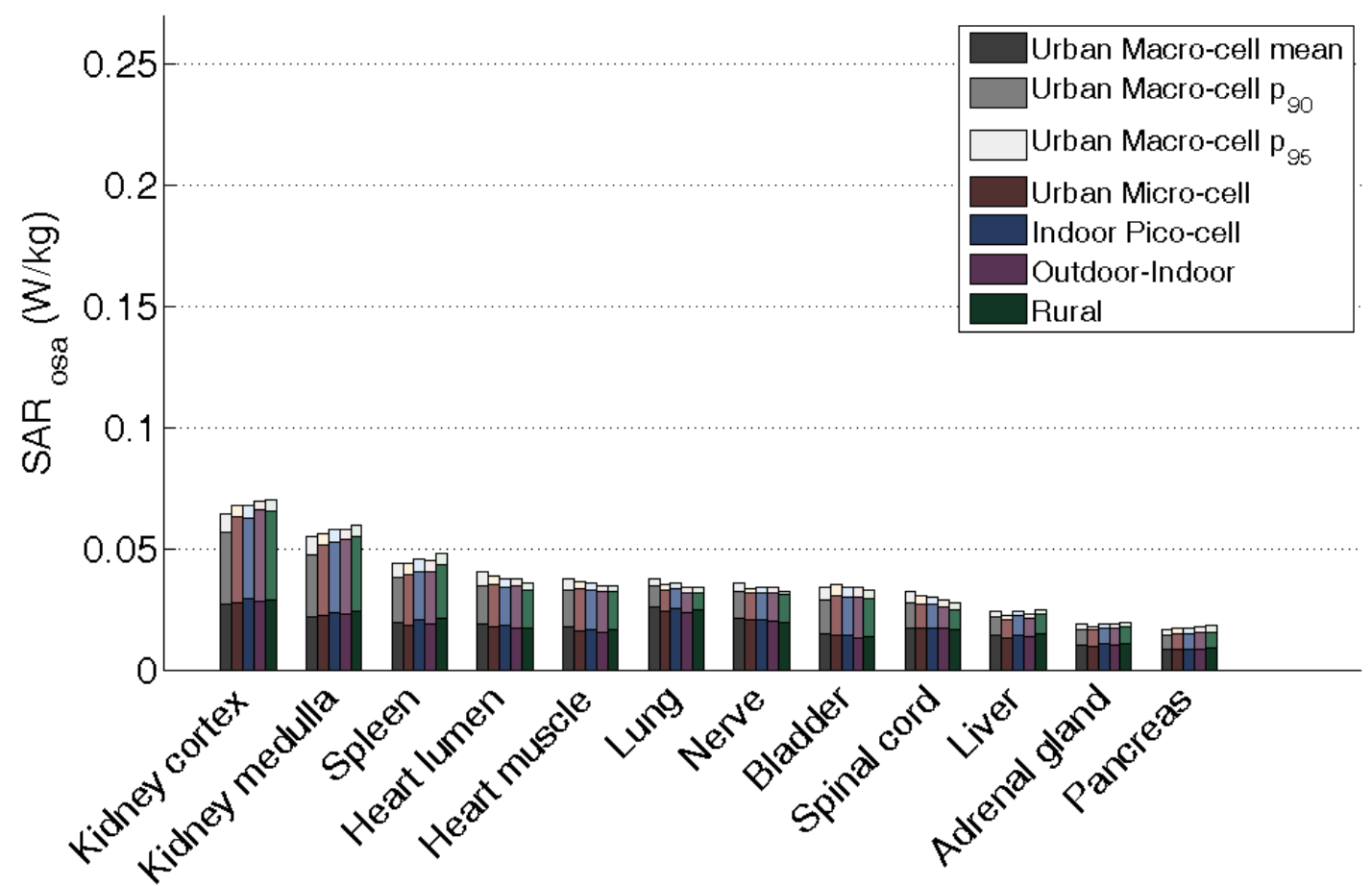

(c)

Figure 3 


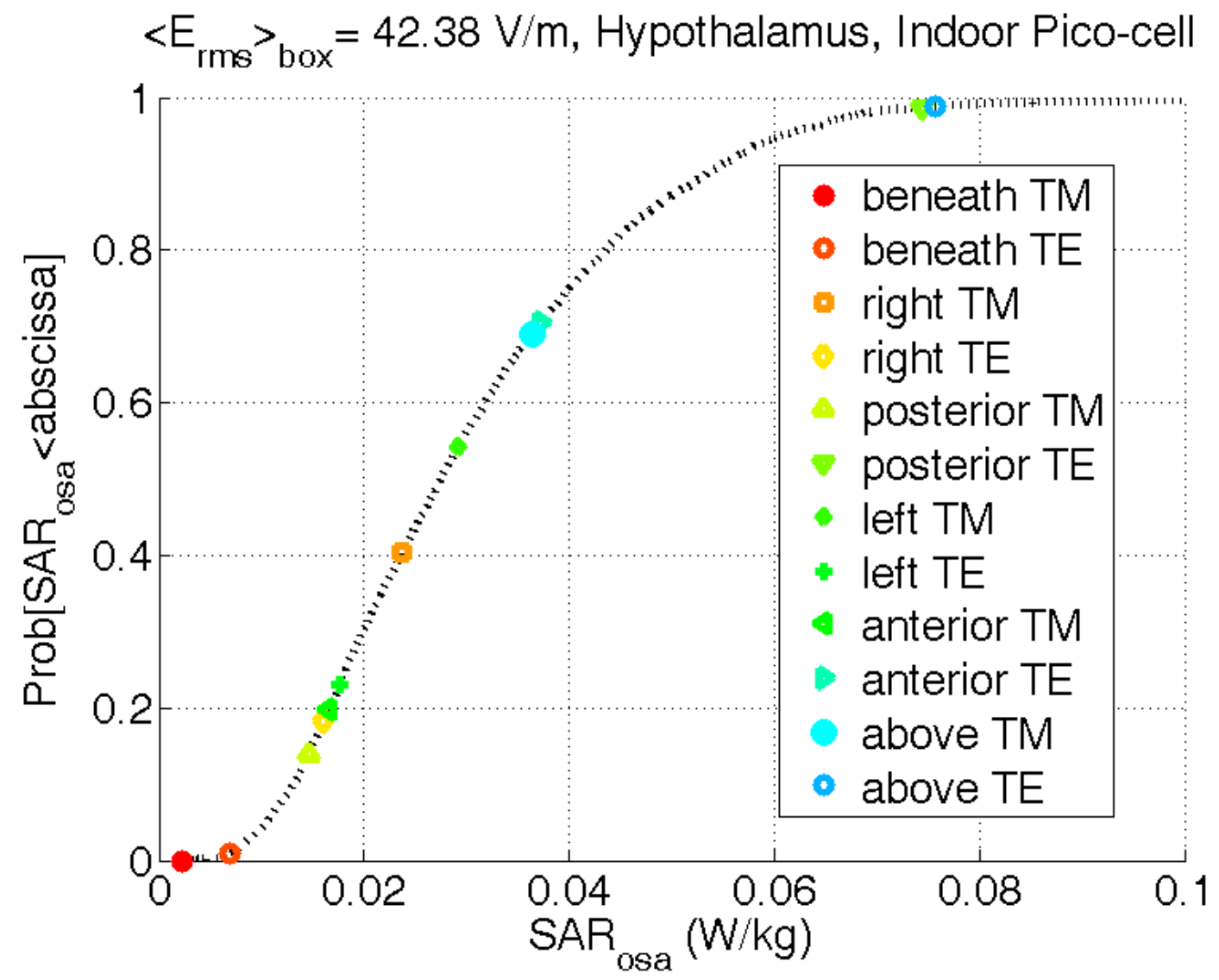

Figure 4 


\section{Supplementary Online Materials}

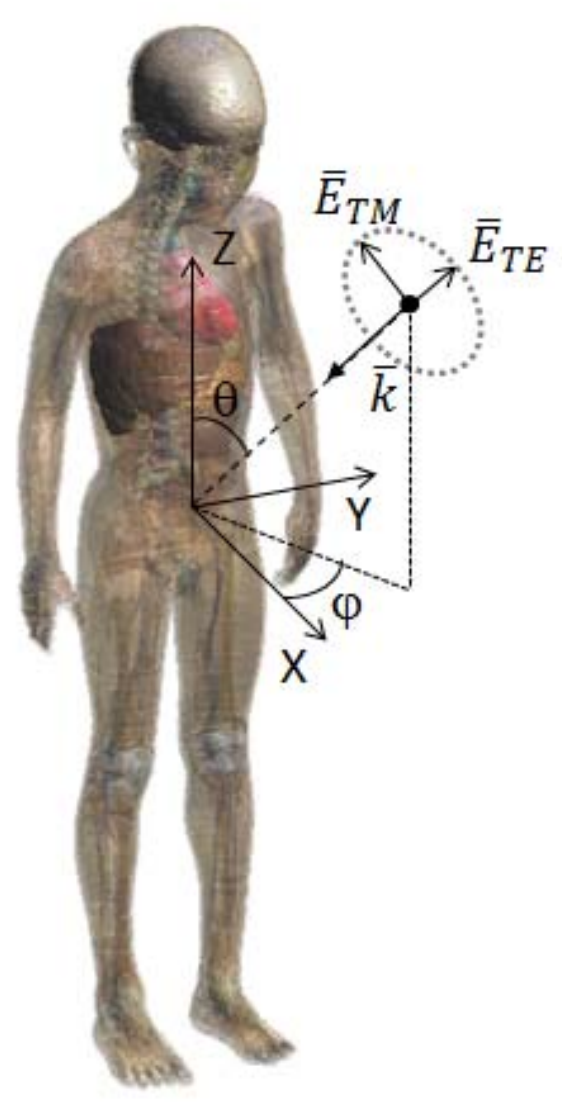

Figure 5

Caption: The Virtual Family boy with an illustration of the spherical coordinates $(\varphi, \theta)$ and two orthogonally polarized plane waves $\left(\bar{E}_{T E}\right.$ and $\bar{E}_{T M}$, with propagation vector $\left.\bar{k}\right)$ used to determine the basic fields. 